\title{
Assessment and Comparative Study of Biofilm Formation with frequency of Multi Drug Resistance in strains of Staphylococcus aureus
}

\author{
Kiran Fatima*, Kashif Ali. \\ Department of Biosciences, Faculty of Life Sciences, Shaheed Zulfikar Ali Bhutto Institute of Science and \\ Technology (SZABIST), Karachi, Pakistan. \\ *Corresponding Author: dr.kashif.ali@szabist.pk
}

\begin{abstract}
Background: The study was conducted to identify the role of biofilms in the antibiotic susceptibility in the strains of Staphylococcus aureus. A total of 19 non repeated pus/wound swab samples from different anatomic locations and 17 samples that were previously identified as $S$. aureus and preserved in the labs were included in the study. The Staphylococcus aureus was identified on the basis of colony morphology, Gram's stain, biochemical tests (catalase and coagulase tests) and molecular identification through PCR amplification. Methodology: A total of 26 samples were recovered out of the 31 samples. Kirby-Bauer disk diffusion susceptibility test was used to determine the sensitivity or resistance of $S$. aureus to methicillin. Out of the 26 strains, 4 were highly resistant, 10 were moderately resistant and 12 strains were sensitive. Three different protocols (Tube Method, Congo Red Agar Method and Tissue Culture plate method) were used for the detection of biofilm formation for both resistant and sensitive strains. Result: Comparative analysis of the antibiotic susceptibility and biofilm formation by different protocols showed that $70 \%$ strains that are resistant to antibiotic methicillin produced moderate-strong biofilms. $50 \%$ have produced the moderate-strong biofilms in all 3 protocols. In case of sensitive, $50 \%$ strains had produced none-weak biofilms in all 3 protocols. Decisions: The strains that had zone of inhibition of close to resistance produced weak-strong biofilms but they all produced weak biofilms in CRA method. It can be concluded that the strains of $S$. aureus that have the ability to produce biofilms become methicillin resistant. Keywords: Biofilm, antibiotic susceptibility, Congo Red Agar, Tube Method, Tissue culture plats.
\end{abstract}




\section{Introduction:}

1.1 Staphylococcus aureus: Staphylococcus aureus is a gram-positive, microorganism species that colonizes the anterior nares of around 20-25\% human population, and 75-80\% are intermittently colonized (Fenny Reffuveillle, 2017). Methicillin-resistant staphylococci aureus (MRSA) is one of the most important infective agents. It is the cause for several diseases from skin to serious invasive infections like respiratory disorder, infections of soft tissues, bones, heart valves, and even fatal blood disorder in humans (Gordon \& Lowy, 2008).

\subsection{Staphylococcus aureus Biofilms}

The genetic and molecular basis of biofilm formation in staphylococci is varied. The flexibility to create a biofilm affords a minimum of 2 properties: the adherence of cells to a

41 surface and accumulation to form multilayered cell clusters. A trade mark is that the production

42 of the slime substance polysaccharide intracellular adhesion (PIA), a carbohydrate composed of 43 beta - one,6 - linked N-acetyl glucosamine with part diacetylated residues, in which the cells are 44 embedded and guarded against the host's immune defense and antibiotic treatment. 45 Staphylococcus aureus is an opportunistic infective agent that produces biofilms on medical 46 equipment and causes respiratory disorder, meningitis, carditis, osteitis and blood poisoning. The 47 biofilm formation by $S$. aureus involves complicated processes. The biofilm cells are controlled along and exhibit an altered composition with relevance micro-organism physiology, metabolism and gene transcription.

\section{Materials \& Methods}

\section{$51 \quad 2.1$ Isolation and collection of Staphylococcus aureus}

52 Staphylococci are gram positive organisms reside in the nasal cavity and other mucous

53 membranes as well as skin of the humans. 19 skin samples were collected by gently rubbing the

54 tip of sterile cotton swab on the face of students at SZABIST 100 and 154 campuses. 17 samples that were preserved at campus lab were acquired. 


\subsection{Growth on Mannitol Salt Agar (MSA)}

MSA is thought to be a selective media for S. aureus. Staphylococci can survive the high salt concentrations of MSA and thus grow without any problem. When mannitol is incited, the acid formed turns the phenol red $\mathrm{pH}$ indicator from red (base) to yellow (acid). All of the 19 swabs were streaked onto a small (one forth) section MSA plate using aseptic technique. The plates were left in incubator at $37^{\circ} \mathrm{C}$ for 24 hours.

\begin{tabular}{|c|c|c|c|}
\hline Test & Staphylococcus aureus & Staphylococcus epidermidis & Staphylococcus saprophyticus \\
\hline Mannitol fermentation & Positive & Negative & Usually Positive \\
\hline
\end{tabular}

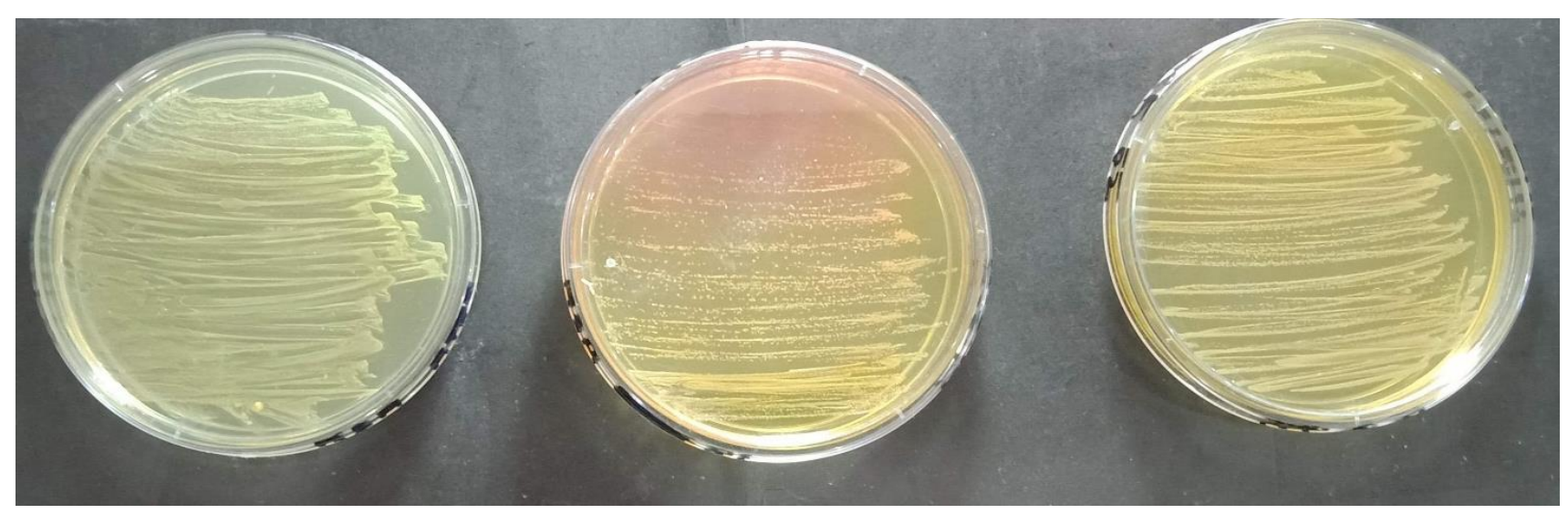

Figure. Growth of Staph Aureus on MSA.

\subsection{Identification of Biochemical Characterization:}

\subsubsection{Catalase Test:}

Streptococci (that is catalase-negative) and staphylococci (which are catalase positive) were differentiated through catalase test. On a microscope slide small number of colonies grown on MSA were placed followed by few drops of $3 \% \mathrm{H}_{2} \mathrm{O}_{2}$. Bubbles are produced at once if the sample contains staphylococci. This therefore, differentiated between streptococci and staphylococci. 31 samples were catalase positive and were separated and sub cultured. The ones that were catalase negative (did not produced the bubbles) were safely discarded.

\subsubsection{Catalase Test Result:}

\begin{tabular}{|c|c|c|}
\hline Test & $\begin{array}{c}\text { Staphylococci } \\
\text { Positive }\end{array}$ & Streptococci \\
\hline Bubble Formation & Negative \\
\hline & & \\
\hline & & \\
\hline
\end{tabular}


72 Figure. Staphylococci species forming bubbles when reacted with Hydrogen peroxide.

\section{2.4.1. Coagulase Test:}

74 Coagulase test was performed to differentiate the S. aureus from other species of Staphylococci 75 as only $S$. aureus has the ability to clot the blood plasma. Hence isolating the $S$. aureus from 76 other species of staphylococci. Out of the 31 samples that were tested for coagulase test 26 were 77 coagulase positive.

\subsubsection{Coagulase Test Result:}

\begin{tabular}{|c|c|c|c|}
\hline Test & Staphylococcus aureus & Staphylococcus epidermidis & Staphylococcus saprophyticus \\
\hline Coagulase Production & Positive & Negative & Negative \\
\hline
\end{tabular}

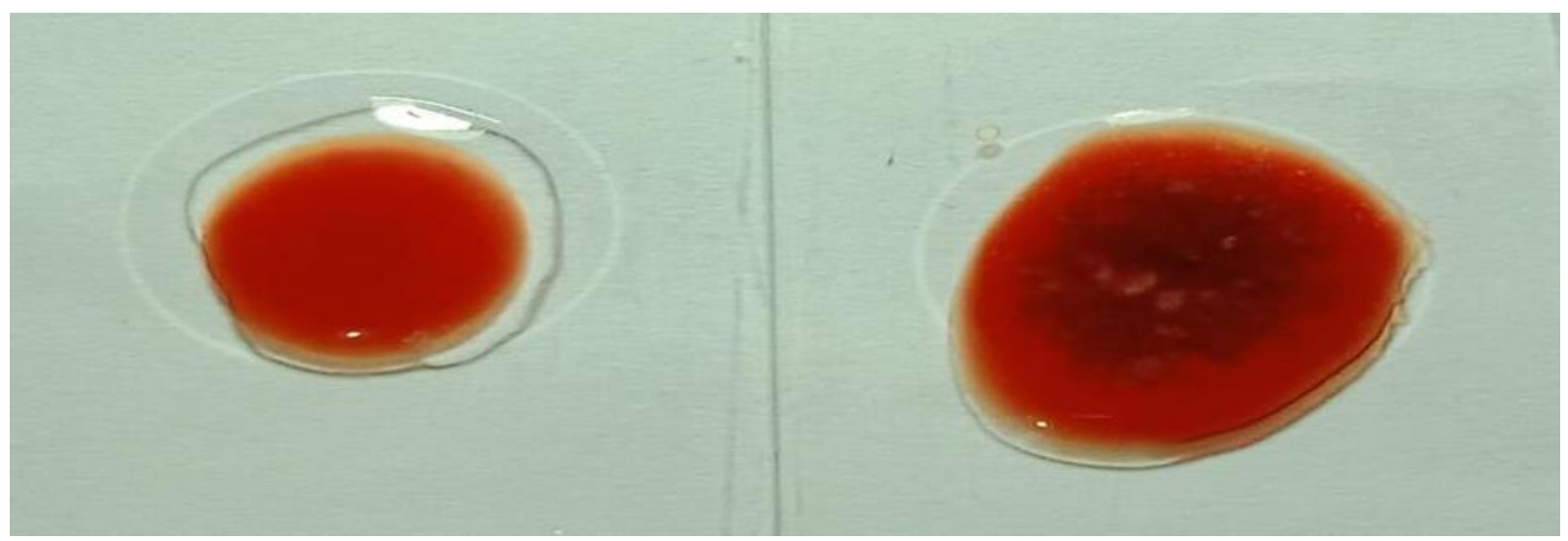

Figure. Coagulase test.

\subsection{Testing $S$. aureus for Methicillin Resistance:}

81 Kirby-Bauer disk diffusion susceptibility test was used to determine the sensitivity or resistance of $S$. aureus to methicillin. The inhibition zone diameters were measured in millimeters using

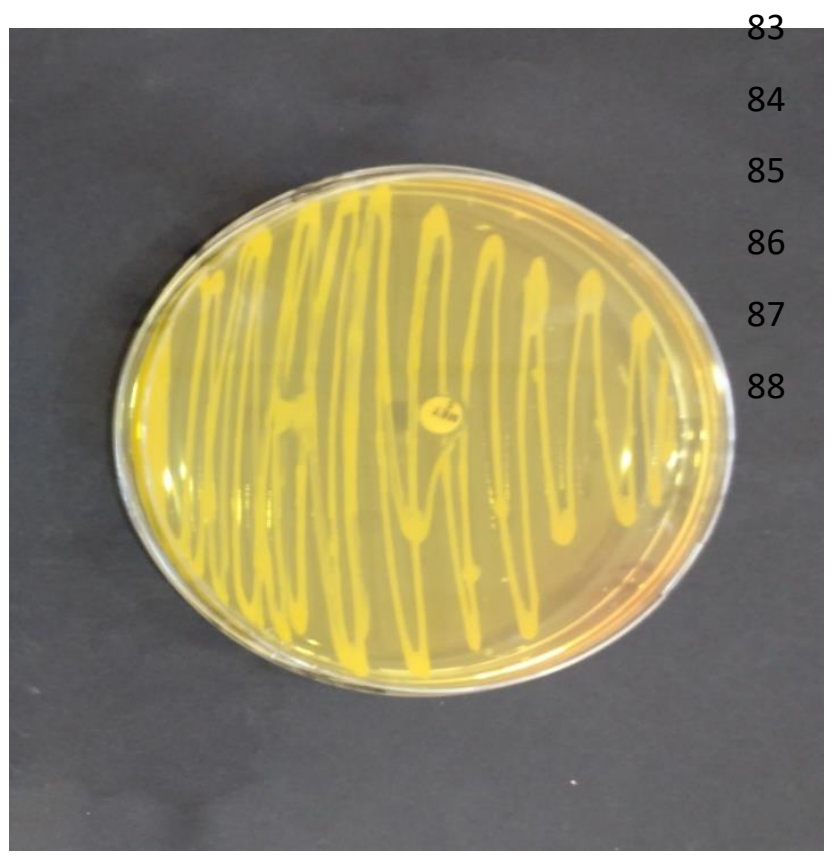
plastic (transparent) meter rule. The results were interpreted according to CLSI guidelines. An inhibition zone diameter of $\leq 13 \mathrm{~mm}$ was reported as methicillin resistant and $\geq 14 \mathrm{~mm}$ was reported as methicillin sensitive (Maj Puneet Bhatt \& Kundan Tandel, 2013). 
90 Methicillin Resistant Strain with no inhibition zone.

91 Methicillin Sensitive Strain with inhibition

\section{$\underline{\text { Nature }}$}

Highly resistant $(9 \mathrm{~mm}$ or less)

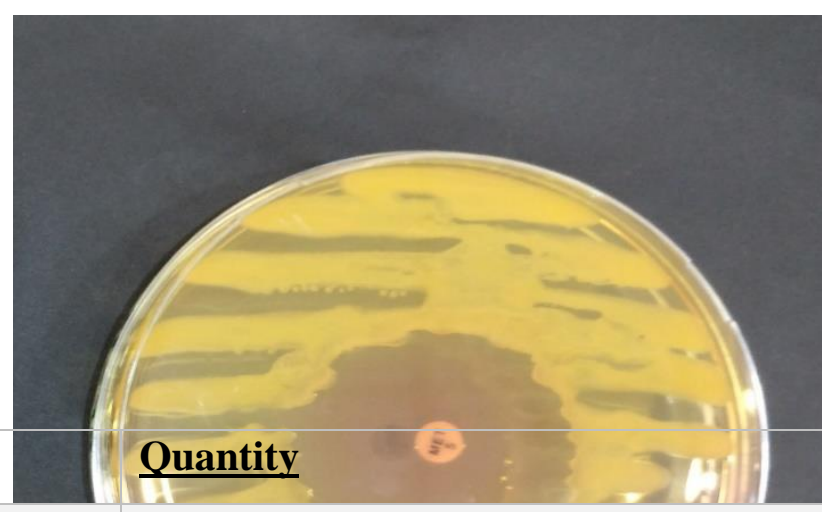

4

Moderately resistant (greater than $10 \mathrm{~mm} \leq 13 \mathrm{~mm}$ ) $\quad 10$

Sensitive (greater than $13 \mathrm{~mm}$ )

12

Total

resistance:

*the reference for zone of inhibition was obtained from (Diagnostics)

10 Resistant and 10 Sensitive strains were selected and were sub cultured for preservation and

\begin{tabular}{|l|l|}
\hline Strain Name & Zone of Inhibition diameter/mm \\
\hline$\underline{\text { Resistant }}$ & 13 \\
\hline $\boldsymbol{R} \mathbf{R 2}$ & 13 \\
\hline $\boldsymbol{R 3}$ & 13 \\
\hline $\mathbf{R 4}$ & 13 \\
\hline
\end{tabular}




\begin{tabular}{|c|c|}
\hline$R 5$ & 12 \\
\hline$R 6$ & 12 \\
\hline$R 7$ & 09 \\
\hline$R 8$ & 08 \\
\hline$R^{9}$ & 02 \\
\hline$R 10$ & 00 \\
\hline \multicolumn{2}{|l|}{ Sensitive } \\
\hline$S 1$ & 14 \\
\hline$S 2$ & 14 \\
\hline$S 3$ & 14 \\
\hline$S 4$ & 14 \\
\hline S5 & 14 \\
\hline S6 & 19 \\
\hline S7 & 21 \\
\hline S8 & 22 \\
\hline S9 & 23 \\
\hline S10 & 23 \\
\hline
\end{tabular}

2.7 Names Assigned and Zone of Inhibition of the Strains that were used for the rest of the Study

105 To determine the relationship between the nature of the strains and biofilm production the 106 following protocols were performed.

\section{$107 \quad 2.9$ Protocol 1: Tube method}

108 Trypticase soy broth (TSB) was prepared with $1 \%$ glucose and poured in to the test tube. After 109 the media was autoclaved colonies of each strains were transferred in to separate tubes and tubes 
110 placed in incubator. After 24 hours the cultures of tubes were discarded and tubes were washed

111 with phosphate buffer saline (PBS) pH 7.3. Tubes were left to dry. $0.1 \%$ crystal violet stain was

112 prepared and tubes were stained with it. Excess stain was discarded and tubes were washed with

113 deionized water. The strains that produced biofilms formed a visible line on the side (wall) and

114 bottom of the tube. Tubes were examined and amount of biofilm formation was scored as 0 -

115 absent, 1-weak, 2-moderate, 3-strong (Deka, 2014)

\section{Tube Method Results:}

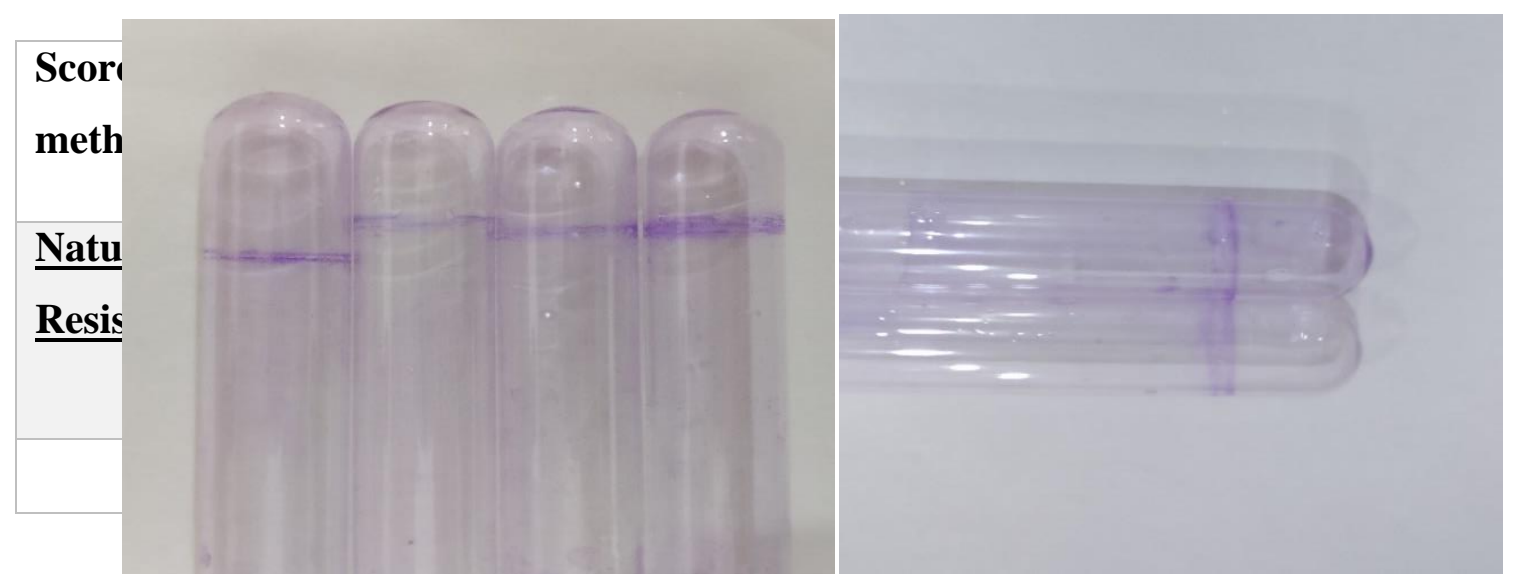

Figure. Visible film lining the wall and bottom of the tube is indicative of biofilm formation

\begin{tabular}{|c|c|c|}
\hline & $R 10, R 09$ & 3 \\
\hline & $\begin{array}{l}R 08, \quad R 07, \\
R 06\end{array}$ & 2 \\
\hline & $\begin{array}{l}R 05, \quad R 04, \\
R 03, R 02\end{array}$ & 1 \\
\hline & $R 01$ & 0 \\
\hline \multirow[t]{4}{*}{$\begin{array}{l}\text { Nature } \\
\text { Sensitive }\end{array}$} & $\underline{\text { Strains }}$ & $\begin{array}{l}\text { Biofilm } \\
\text { production } \\
\underline{\text { score }}\end{array}$ \\
\hline & $\mathrm{SO}, \mathrm{SO2}$ & 3 \\
\hline & $\begin{array}{l}\text { S03, } \\
\text { S05 }\end{array}$ & 2 \\
\hline & $\begin{array}{l}\text { S06, S08, } \\
\text { S10 }\end{array}$ & 1 \\
\hline
\end{tabular}




\subsection{Protocol 2: Congo Red Agar Method (CRA)}

120 A special medium which was mixture of Brain Heart infusion agar (37 gm/l), sucrose (5gm/l), agar no $1(10 \mathrm{gm} / \mathrm{l})$ and Congo red dye $(0.8 \mathrm{gm} / \mathrm{l})$ was produced. After the medium was 122 autoclaved it was poured into the plates and strains were streaked onto the plates. Plates were 123 incubated for 24 to 48 hours. The strains that produced strong biofilms formed black colonies and the ones that remained pink indicated weak biofilm production.

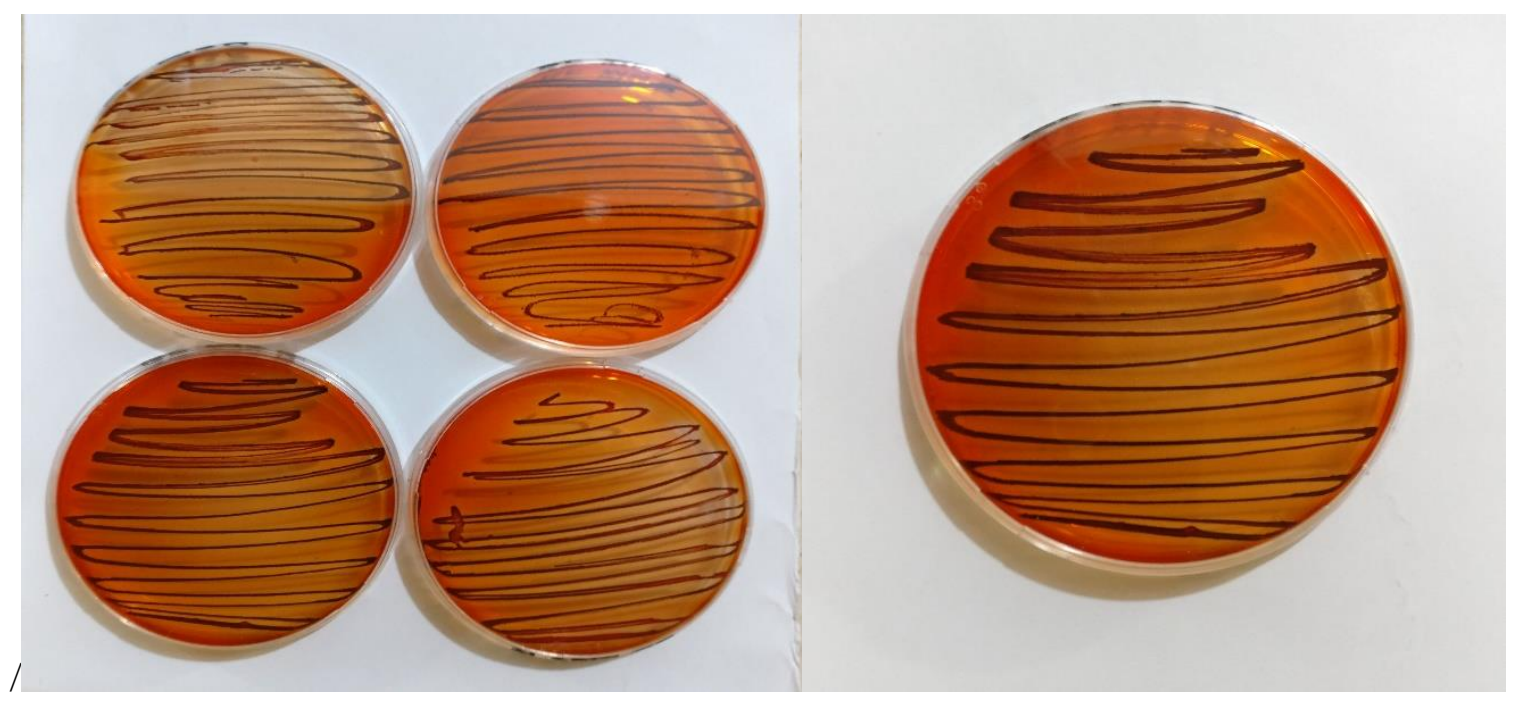

127 Figure. Black colonies indicating the production of strong biofilms.
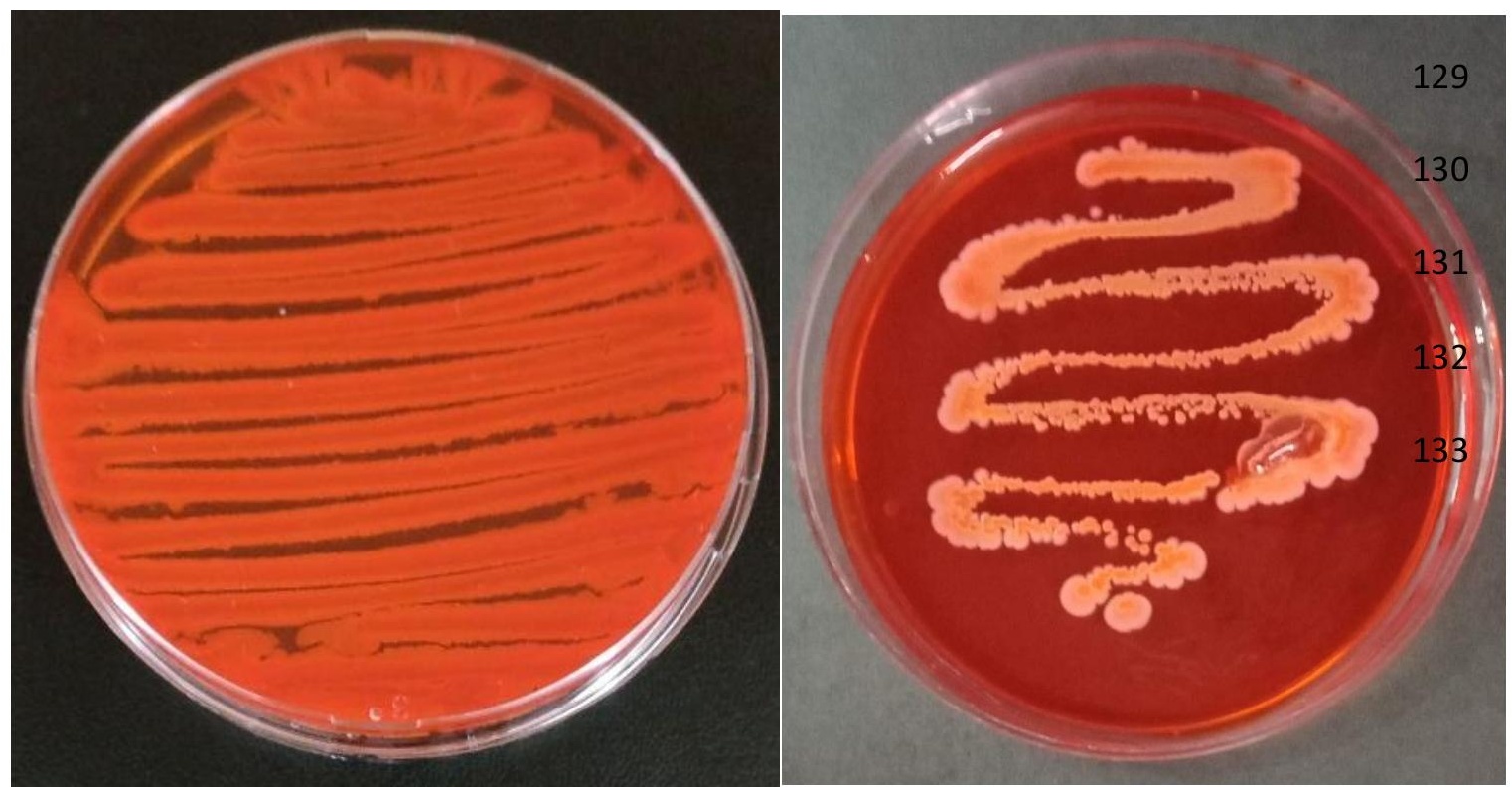
Figure Week biofilm producing stained remained pink.

\section{Biofilm Production by CRA Method Results}

\begin{tabular}{|l|l|l|}
\hline$\underline{\text { Nature }}$ & $\underline{\text { Strain }}$ & Biofilm production \\
\hline$\underline{\text { Resistant }}$ & $\begin{array}{l}\text { R10, R09, R08, R07, R06, } \\
\text { R04 Strong }\end{array}$ \\
\hline R05, R03, R02, R01 & Moderate-Strong \\
\hline$\underline{\text { Sensitive }}$ & SO1, S02, S03, S04, S05 & Weak \\
\hline & $S 06, S 07, S 08, S 09, S 10$ & None \\
\hline
\end{tabular}

\subsection{Protocol 3: Tissue Culture Plate Method (TCP)}

Tryptic soy broth (TSB) was prepared with $1 \%$ glucose and poured in to the test tube. After the media was autoclaved colonies of each strains were transferred in to separate tubes and tubes placed in incubator. After 24 hours the cultures from tubes were poured into the 96 wells flat

144 bottom micro-titre plate. Aluminum foil was used to cover the plate and plate was placed in the 145 incubator for 24 hours. The cultures from wells were then discarded and wells were washed with 146 PBS. $0.1 \%$ crystal violet stain was prepared and wells were stained with it. Excess stain was 147 discarded and wells were washed with deionized water. Optical density of each well was 148 measured at $570 \mathrm{~nm}$ using an automated ELISA plate reader. 
Figure. Micro-titre plate stained with crystal violet.

155

\section{Tissue Culture Plate Optical Densities}

\begin{tabular}{|l|l|l|}
\hline Mean OD Values & Adherence & Biofilm Formation \\
\hline$<0.120$ & None & None/weak \\
\hline $0.120-0.199$ & Moderate & Weak \\
\hline $0.200-0.239$ & Strong & Moderate \\
$\geq 0.240$ & & High \\
\hline
\end{tabular}

156 Classification of Bacterial Adherence by TCP Method (Pragyan Swagatika Panda \& Dube, 157 2016)

167 OD Values obtained by TCP Method Results:

\section{$\underline{\text { Resistant }}$}




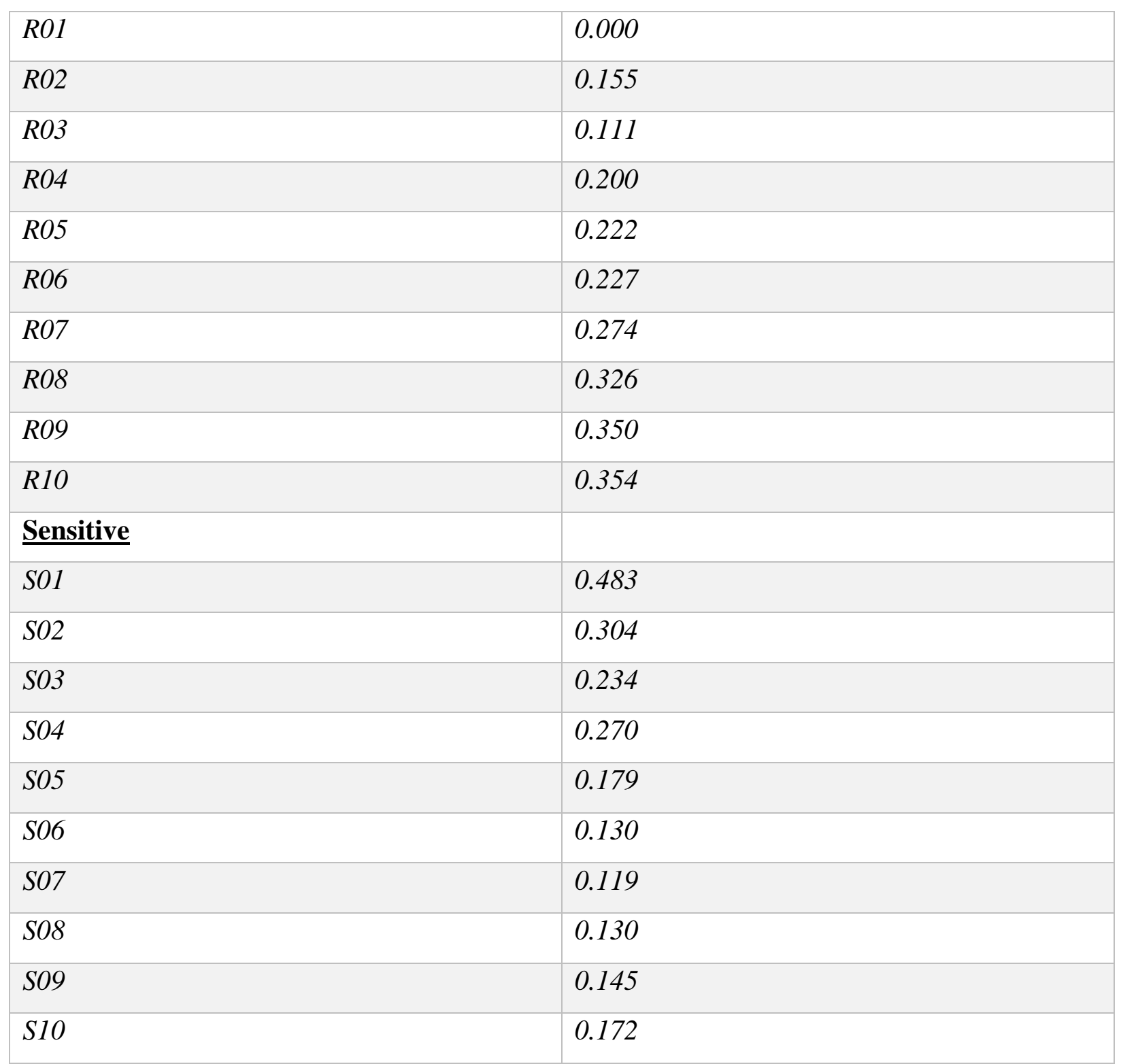


Results:

170 Comparative Analysis of the Antibiotic Susceptibility and Biofilm formation by 3 different 171 protocols.

\begin{tabular}{|c|c|c|c|c|}
\hline \multirow[t]{2}{*}{ Strain } & \multirow{2}{*}{$\begin{array}{c}\text { Zone of Inhibition } \\
\text { Diameter/mm }\end{array}$} & \multicolumn{3}{|c|}{ Biofilm Production By } \\
\hline & & Tube Method & CRA Method & TCP Method \\
\hline \multicolumn{5}{|l|}{ Resistant } \\
\hline R01 & 13 & Absent & Moderate - Strong & None \\
\hline RO2 & 13 & Weak & Moderate - Strong & Weak \\
\hline R03 & 13 & Weak & Moderate - Strong & None/Weak \\
\hline R04 & 13 & Weak & Strong & Moderate \\
\hline R05 & 12 & Weak & Moderate - Strong & Moderate \\
\hline R06 & 12 & Moderate & Strong & Moderate \\
\hline RO7 & 09 & Moderate & Strong & Strong \\
\hline R08 & 08 & Moderate & Strong & Strong \\
\hline RO9 & 02 & Strong & Strong & Strong \\
\hline$R 10$ & 00 & Strong & Strong & Strong \\
\hline \multicolumn{5}{|l|}{ Sensitive } \\
\hline S01 & 14 & Strong & Weak & Strong \\
\hline SO2 & 14 & Strong & Weak & Strong \\
\hline SO3 & 14 & Moderate & Weak & Moderate \\
\hline SO4 & 14 & Moderate & Weak & Strong \\
\hline SO5 & 14 & Moderate & Weak & Weak \\
\hline SO6 & 19 & Weak & None & Weak \\
\hline SO7 & 21 & None & None & None/Weak \\
\hline S08 & 22 & None & None & Weak \\
\hline sog & 23 & None & None & Weak \\
\hline S10 & 23 & Weak & None & Weak \\
\hline
\end{tabular}

172 


\section{Discussion:}

181 Comparative analysis of the antibiotic susceptibility and biofilm formation by 3 different 182 protocols shows that $70 \%$ strains that are resistant to antibiotic methicillin produced moderatestrong biofilms. 50\% have produced the moderate-strong biofilms in all 3 protocols which are

184 R10 till R06. R04 and R05 have produced moderate-strong biofilms in CRA and TCP method. 185 R09 and R10 have produced strong biofilms in all three protocols and both of them had zone of 186 inhibitions of 2 and 0 millimeters respectively, this therefore supports the argument that the more 187 the resistance to methicillin the stronger the biofilm is produced and perhaps more chance of 188 producing biofilms.

189 In case of sensitive, $50 \%$ strains had produced none-weak biofilms in all 3 protocols. The strains 190 that had zone of inhibition of 14 millimeters which are S01 till S05 produced weak-strong 191 biofilms but they all produced weak biofilms in CRA method. This supports the argument that as 192 these strains were almost near the antibiotic resistance which is less than or 13 millimeters 193 therefore, they produced biofilms but as they were not completely resistant, they were unable to 194 produce biofilms in all 3 protocols. Strains S06 till S10 had no or weak biofilms in all protocols 195 and as these strains had zone of inhibition greater than 18 millimeters which is far from 196 resistance this supports the argument that the less the resistance to methicillin the weaker the 197 biofilm is produced or perhaps the less chance of producing the biofilms.

199 Conclusion:

200 The nature of biofilm structure and therefore the physiological attributes of biofilm organisms 201 have inherent resistance to antimicrobial agents, no matter these antimicrobial agents are 202 antibiotics or disinfectants. From the results obtained from the study it can be concluded that the 203 greater the resistance to methicillin, the stronger biofilm is produced and less the resistance to 204 methicillin the weaker the biofilm is produced or perhaps the less chance of producing the 205 biofilms. 
Furthermore, the strains of $S$. aureus that have the ability to produce biofilms become methicillin resistant. This supports the argument that biofilms play major role in providing the antibiotic resistance to bacteria.

Biofilm-producing strains of $S$. aureus pose a serious threat in health sectors. These strains of bacteria are encased in a matrix that allows them to resist and exclude antibiotics and also the host immune response. In addition to having structural barriers, the strains can rapidly undergo physiological changes such as slow growth rate and producing persistent cells. In these conditions, antibiotics fail to inhibit, kill, or eradicate these cells which are found inside the biofilm matrix. Therefore, chronic infections caused by biofilms are often difficult to treat effectively in part due to the resistance of biofilms to antimicrobial therapy. In general, antimicrobial resistance along with biofilm formation becomes an escalating and intractable problem in the health sector.

Acknowledgement: Special thanks to Mr. Khair Bux and Ms Asma Bashir for proof reading the article, writing assistance.

Funding: This work was supported by the Shaheed Zulfikar Ali Bhutto Institute of Science and Technology.

Conflicts of Interest: The author declares that there are no conflicts of interest in regard to the publication of this paper.

\section{References:}

1. Brown AF, Leech JM, Rogers TR, McLoughlin RM. Staphylococcus aureus colonization: modulation of host immune response and impact on human vaccine design. Frontiers in immunology. 2014 Jan 8; 4:507.

2. Annous BA, Fratamico PM, Smith JL. Scientific status summary: Quorum sensing in biofilms: Why bacteria behave the way they do. Journal of food science. 2009 Jan;74(1): R24-37.

3. Davies D. Understanding biofilm resistance to antibacterial agents. Nature reviews Drug discovery. 2003 Feb;2(2):114-22.

4. De la Fuente-Núñez C, Reffuveille F, Fernández L, Hancock RE. Bacterial biofilm development as a multicellular adaptation: antibiotic resistance and new therapeutic strategies. Current opinion in microbiology. 2013 Oct 1;16(5):580-9.

5. Deka N. Comparison of Tissue Culture plate method, Tube Method and Congo Red Agar Method for the detection of biofilm formation by Coagulase Negative Staphylococcus isolated from Nonclinical Isolates. Int J Curr Microbiol App Sci. 2014 Nov;3(10):810-5. 
6. Bauer AW. Antibiotic susceptibility testing by a standardized single disc method. Am J clin pathol. 1966; 45:149-58.

7. Reffuveille F, Josse J, Vallé Q, Gangloff CM, Gangloff SC. Staphylococcus aureus Biofilms and their Impact on the Medical Field. The rise of virulence and antibiotic resistance in Staphylococcus aureus. 2017 Mar 8; 11:187.

8. Fournier PE, Richet $H$, Weinstein RA. The epidemiology and control of Acinetobacter baumannii in health care facilities. Clinical infectious diseases. 2006 Mar 1;42(5):692-9.

9. Gordon RJ, Lowy FD. Pathogenesis of methicillin-resistant Staphylococcus aureus infection. Clinical infectious diseases. 2008 Jun 1;46(Supplement_5): S350-9.

10. Lewis K. Persister cells. Annual review of microbiology. 2010 Oct 13; 64:357-72.

11. Jefferson KK. What drives bacteria to produce a biofilm? FEMS microbiology letters. 2004 Jul 1;236(2):163-73.

12. Kluytmans JA, Van Belkum A, Verbrugh H. Nasal carriage of Staphylococcus aureus: epidemiology, underlying mechanisms, and associated risks. Clinical microbiology reviews. 1997 Jul;10(3):505-20.

13. López D, Vlamakis H, Kolter R. Biofilms. Cold Spring Harbor perspectives in biology. 2010 Jul 1;2(7): a000398.

14. Melzer M, Welch C. Thirty-day mortality in UK patients with community-onset and hospitalacquired meticillin-susceptible Staphylococcus aureus bacteraemia. Journal of Hospital Infection. 2013 Jun 1;84(2):143-50.

15. Bashir A, Farid N, Ali K, Fatima K. Development of Biofilms for Antimicrobial Resistance. InPathogenic Bacteria 2019 Nov 29. IntechOpen.

16. Panda PS, Chaudhary U, Dube SK. Comparison of four different methods for detection of biofilm formation by uropathogens. Indian Journal of Pathology and Microbiology. $2016 \mathrm{Apr}$ 1;59(2):177.

17. Neyra RC, Frisancho JA, Rinsky JL, Resnick C, Carroll KC, Rule AM, Ross T, You Y, Price LB, Silbergeld EK. Multidrug-resistant and methicillin-resistant Staphylococcus aureus (MRSA) in hog slaughter and processing plant workers and their community in North Carolina (USA). Environmental health perspectives. 2014 May;122(5):471-7.

18. Scherr TD, Heim CE, Morrison JM, Kielian T. Hiding in plain sight: interplay between staphylococcal biofilms and host immunity. Frontiers in immunology. 2014 Feb 5; 5:37.

19. Bekele ST, Abay GK, Gelaw B, Tessema B. Bacterial biofilms; links to pathogenesis and resistance mechanism.

20. Dunne Jr WM. Bacterial adhesion: seen any good biofilms lately? Clinical microbiology reviews. 2002 Apr;15(2):155-66. 
bioRxiv preprint doi: https://doi.org/10.1101/2021.12.16.473079; this version posted December 17, 2021. The copyright holder for this preprint (which was not certified by peer review) is the author/funder. All rights reserved. No reuse allowed without permission. 